\title{
Fluvial transport potential of shed and root-bearing dinosaur teeth from the late Jurassic Morrison Formation
}

Shed dinosaur teeth are commonly collected microvertebrate remains that have been used for interpretations of dinosaur feeding behaviors, paleoecology, and population studies. However, such interpretations may be biased by taphonomic processes such as fluvial sorting influenced by tooth shape: shed teeth, removed from the skull during life, and teeth possessing roots, removed from the skull after death. As such, teeth may behave differently in fluvial systems due to their differences in shape. In order to determine the influence of fluvial processes on the preservation and distribution of shed and root-bearing dinosaur teeth, the hydrodynamic behaviors of high-density urethane resin casts of shed and rootbearing Allosaurus and Camarasaurus teeth were experimentally tested for relative transport distances at increasing flow velocities in an artificial fluviatile environment. Results show that tooth cast specimens exhibited comparable patterns of transport at lower velocities, though the shed Camarasaurus teeth transported considerably farther in medium to higher flow velocities. Two-Way ANOVA tests indicate significant differences in the mean transport distances of tooth casts oriented perpendicular to flow $(p<0.05)$ with varying tooth morphologies and flow velocities. The differences exhibited in the transportability of shed and root-bearing teeth has important implications for taphonomic reconstructions, as well as future studies on dinosaur population dynamics, paleoecology, and feeding behaviors. 
Experiments on the transport of skeletal remains in controlled fluvial systems have been

3 of significant use in deciphering relative hydrodynamic properties and behaviors of remains in

4 vertebrate taphonomic studies (e.g. Voorhies, 1969; Behrensmeyer, 1975; Boaz and

5 Behrensmeyer, 1976; Hanson, 1980; Blob, 1997; Nasti, 2005; Peterson and Bigalke, 2013). A

6 majority of previous flume experiments have been conducted on a variety of macrovertebrate

7 taxonomic groups, such as mammals and dinosaurs (e.g. Voorhies, 1969; Behrensmeyer, 1975;

8 Boaz and Behrensmeyer, 1976; Coard and Dennell, 1995; Coard, 1999; Nasti, 2005; Peterson and

9 Bigalke, 2013). Although microvertebrate remains are commonly collected and utilized for

10 paleoecological and taphonomic reconstructions, few studies have employed flume experiments

11 to explore the role of differing relative hydrodynamic properties in the development of

12 microvertebrate assemblages or “microsites" (e.g. Dodson, 1973; Blob, 1997; Trapani, 1998).

13 "Microsites" are accumulations of small, fragmentary, moderately to well-sorted fossil

14 material, including largely disarticulated vertebrate remains, typically dominated by fish scales,

15 bone fragments, and shed teeth (Wood et al., 1988). Although scales and bone fragments are of

16 interest for their potential uses in taphonomic reconstructions (e.g. Blob and Fiorillo, 1996;

17 Wilson 2008; Peterson et al, 2011), the abundance of shed dinosaur teeth in Mesozoic deposits is

18 of particular interest in attempts to infer dental physiology (Sereno and Wilson, 2005; D’Emic et

19 al., 2013), feeding behaviors (Jennings and Hasiotis, 2006), paleoecology (Bakker and Bir, 2004),

20 and their potential for population studies (Erickson, 1996).

21 However, interpretations regarding feeding behaviors, paleoecology, and population

22 dynamics based on shed teeth may be biased by taphonomic processes such as fluvial sorting

23 influenced by tooth shape: shed teeth (removed from the skull in vivo) and teeth possessing roots

24 (removed from the skull post-mortem) may behave differently in fluvial settings due to their

25 shape differences. In order to determine the role of fluvial processes on the preservation and 
26 distribution of shed and root-bearing dinosaur teeth, an experiment was conducted to ascertain

27 the hydrodynamic properties of two morphologically distinct sets of dinosaur teeth from Late

28 Jurassic theropods and sauropods. Specifically, the question is addressed: Are the mean transport

29 distances the same for shed and root-bearing teeth at varying flow velocities? Presented here are

30 the results of this experiment and a discussion on the potential biases of shed teeth in the fossil

31 record.

33 UWO-VPC - University of Wisconsin Oshkosh Vertebrate Paleontology Cast Collection,

34 Oshkosh, WI, USA.

\section{MATERIALS AND METHODS}

To test for variation in relative transport distances in theropod and sauropod teeth in

37 fluvial settings, casts were made of four different dinosaur teeth using a urethane resin and placed

38 in a recirculating flume at increasing stages of flow velocity. Casts were chosen instead of fossil

39 teeth in order to avoid damage to delicate fossil specimens, and to maintain a consistent specific

40 gravity among specimens. Tooth casts were produced using Replicator $400^{\mathrm{TM}}$ (Alumilite), which

41 has a cured specific gravity of approximately $1.5 \mathrm{~g} / \mathrm{cm}^{3}$. Enamel and dentine have specific

42 gravities of $2.8 \mathrm{~g} / \mathrm{cm}^{3}$ and $2.3 \mathrm{~g} / \mathrm{cm}^{3}$, respectively (Brekhus and Armstrong, 1935). While the

43 specific gravity of the casting resin is different than that of teeth, relative comparisons can be

44 conducted among cast elements of different shapes with the use of this standardized specific

45 gravity.

46 The four specimens of dinosaur teeth were chosen based on their differences in shape,

47 size, and representation in the fossil record (Blob and Fiorillo, 1996) (Table 1). To model

48 theropod and sauropod teeth associated with post-mortem cranial disarticulation, a single set of

49 casts was produced of root-bearing maxillary tooth specimens of Camarasaurus (UWO-VPC- 
2013.003) and Allosaurus (UWO-VPC-2013.001) (Figure 1A, B). The Camarasaurus tooth cast

51 UWO-VPC-2013.003 was made from a shed crown and attached to a sculpted root. Similarly, to

52 model shed theropod and sauropod teeth associated with tooth regeneration in vivo, a second set

53 of casts were produced (UWO-VPC-2013.002 and UWO-VPC-2013.004) with the root portions

54 of the casts removed (Figure $1 \mathrm{C}, \mathrm{D})$. By using the same tooth crowns of Allosaurus and

55 Camarasaurus and secondarily adding or removing the root portions of the casts for the

56 experiment, more control over the role of attached roots in transport could be observed. The casts

57 used in this study are housed at the University of Wisconsin Oshkosh Department of Geology,

58 and were based on specimens in private collections. Casts were also digitized into 3D models

59 using a NextEngine Desktop 3D Scanner and processed with ScanStudio HD Pro (NextEngine)

60 (Figures S1-S4, Text S1).

61 Transport experiments were conducted at the re-circulating flume at the University of

62 Wisconsin-Oshkosh Department of Geology. The flume measures $0.45 \mathrm{~m}$ deep x $0.15 \mathrm{~m}$ wide and

$633.5 \mathrm{~m}$ in length (Figure 2), and was filled to maintain a depth of $10 \mathrm{~cm}$ during trials. To determine

64 relative transport distances associated with flow velocity, tests were conducted on a planar glass

65 surface in $10 \mathrm{~cm}$ water depth. Each tooth cast was repeatedly placed in the flume perpendicular

66 and parallel to flow (Figure 3A-F) at three different velocity settings; $10.0-19.9 \mathrm{~cm} / \mathrm{sec}, 20.0-$

$6729.9 \mathrm{~cm} / \mathrm{sec}$, and $30.0-39.9 \mathrm{~cm} / \mathrm{sec}$. The apex of the tooth crown was pointed in the upstream

68 direction for trials where the teeth were placed parallel to flow (Figure 3B, D). Additionally, trials

69 ran in the perpendicular direction involved placing the apex of the tooth crown perpendicular to

70 flow (Figure 3A, C). Each test consisted of 10 trials per tooth cast in each orientation and at each

71 velocity stage. To avoid interactions between tooth casts during transport, casts were placed in the

72 flume alone for the duration of the experiment. Total transport distance and flow velocity at the

73 location of settling were collected for each trial. Relative transport distance serves as a proxy for

74 relative time of transport and offers insight into time averaging (Aslan and Behrensmeyer, 1996). 
75 Relative transport distance data also serve as comparisons of the relative transportability among

76 tooth casts. Entrainment velocity, the velocity required to move the casts, was determined by

77 recording the fluvial velocity (HACH FH950 Portable Velocity System) at the location of

78 settling.

Analysis of variance (ANOVA) was employed to compare the mean transport distances of

81 the four tooth casts under different flow velocities. A D'Agustino and Shapiro omnibus test found

82 some data departed from a Gaussian distribution (normality), therefore the data were log-

83 transformed prior to analysis (Sokal and Rohlf, 1995). An initial one-way ANOVA found no

84 significant difference between the transport distances of parallel- and perpendicular-oriented

85 datasets (Figure 4); each dataset is therefore analyzed independently. A two-factor ANOVA

86 followed by a Bonferroni multiple comparisons test was run for each dataset. The Bonferroni test

87 compares the simple effects of tooth cast shape within each velocity range, utilizing a

88 conservative single-family grouping for all comparisons. A nominal significance level of 0.05

89 was used in all ANOVA tests to reject the null hypothesis that the mean transport distances are the

90 same for all tooth shapes and at all flow velocities. All analyses were carried out using Prism

91 version 6.0d for Macintosh (GraphPad Software, La Jolla California USA, www.graphpad.com).

\section{RESULTS}

93 During flume tests, teeth commonly initiated transport by sliding on the bottom of the

94 flume; however, in a few instances, teeth rolled for a short distance and then slid to their final

95 position. Two-factor ANOVA tests produced multiple significant results. Perpendicular tooth

96 casts were found to vary significantly in transport distance due to tooth morphology $(\mathrm{F}=14.9$, 
$97 \mathrm{df}=3, \mathrm{p}<0.0001)$ and flow velocity $(\mathrm{F}=54.35, \mathrm{df}=2, \mathrm{p}<0.0001)$, with a strong interaction effect

$98(\mathrm{~F}=4.865, \mathrm{df}=6, \mathrm{p}=0.0002)$ (Table $2 \mathrm{~A})$. The strong interaction effect is explained by the

99 Bonferroni test results, which indicates that significant differences occur between the shed

100 Camarasaurus tooth and all other tooth cast specimens, mainly at high velocities $(30-39.9 \mathrm{~cm} / \mathrm{s})$

101 (Table 2B). The variability is further enhanced by some other significant differences between

102 teeth in the other flow velocity ranges.

103 Two-factor ANOVA results of tooth casts oriented parallel to flow indicated significant

104 differences in mean transport distance due to tooth morphology $(F=42.80, \mathrm{df}=3, \mathrm{p}<0.0001)$ and

105 flow velocity $(\mathrm{F}=78.45, \mathrm{df}=2, \mathrm{p}<0.0001)$ (Table $2 \mathrm{C})$, with a significant interaction effect

$106(\mathrm{~F}=3.507, \mathrm{df}=6, \mathrm{p}=0.0033)$. The Bonferroni test shows that several comparisons are significantly

107 different across flow velocity ranges; occurring mainly between the shed and rooted teeth (Table 108 2D).

109 The initial orientation of the tooth (parallel vs. perpendicular) had no significant effect on

110 relative transport distance (Figure 4). The most notable difference in hydrodynamic behavior is

111 observed between shed and rooted teeth, where shed teeth on average travelled further than

112 rooted teeth under most conditions (Figure 5A, B). However, the hydrodynamic behavior of each

113 tooth shape varies with flow velocity. At lower flow velocities the teeth behave more similarly to

114 each other, diverging significantly at higher flow velocities. This has been previously noted for

115 other skeletal elements during fluvial transport (e.g. Voorhies, 1969).

117 These results demonstrate a close link between shape differences in vertebrate teeth and 118 their potential representation in a fossil assemblage due to the influence of shape on 
119 hydrodynamic behavior (Behrensmeyer, 1975; Coard and Dennell, 1995; Peterson and Bigalke, 120 2013).

121 Shed and root-bearing teeth differ significantly in hydrodynamic behavior and thus have

122 an increased likelihood of contributing preservational biases; elongate teeth (i.e. root-bearing)

123 and teeth approaching a conical shape (i.e. shed theropod teeth) do not transport as far with

124 increasing flow velocities as compact teeth (i.e. shed Camarasaurus teeth). This suggests that

125 compact teeth have a higher potential for continued transport while elongate and conical teeth are

126 more likely to remain as lag, thus increasing their potential for preservation in the fossil record.

127 This suggestion may be tested by comparing the abundance, taphonomic signatures (i.e.,

128 quartz-grain equivalence, sorting, weathering, etc.), and proximity of root-bearing teeth to their

129 original cranial elements. Indeed, root-bearing teeth are typically discovered relatively close to

130 other skeletal remains, as they were removed during post-mortem cranial disarticulation and show

131 relatively little transport (e.g. Breithaupt, 2001; Lehman and Coulson, 2002; Derstler and Myers,

132 2008). This is also supported by the high frequency of shed theropod teeth associated with

133 proposed feeding sites (e.g. Argast et al., 1987; Bakker, 1997; Jennings and Hasiotis, 2006;

134 Roach and Brinkman, 2007). However, the presence of both root-bearing and shed teeth of a

135 variety of Jurassic dinosaurs in multi-taxa bonebeds (e.g. Cleveland Lloyd Dinosaur Quarry, Nail

136 Quarry, and Quarry 9) may indicate a more complex origin of such assemblages, and require an

137 understanding of the hydrodynamic properties of both root-bearing and shed teeth. Assessing the

138 complexity of a tooth assemblage could be accomplished by measuring the relative proportions of

139 each tooth shape (compact, conical, and elongate) present in the sample. Excessive numbers of

140 compact teeth, for example, could be evidence of a heavily reworked or allochthonous origin of

141 teeth in the assemblage.

142 These results provide further support for an interaction between conditions in the 143 depositional environment and transported elements. Despite finding no statistically significant 
144 difference in average transport distance between perpendicular and parallel orientations, a great

145 degree of variability occurred within and between the different velocity ranges. Hydrodynamic

146 behavior (as measured by relative transport distance) depended on the flow velocity. If flow

147 conditions were not interacting with the hydrodynamic properties of each tooth, one would

148 expect to see a linear response and relatively fixed differences among all tooth morphologies.

149 Non-linear responses were found across all velocity ranges and tooth morphologies. This

150 variability is most apparent in perpendicular-oriented trials. Environment of deposition plays a

151 role in assembly of lags and microsites (Rogers and Brady, 2010). More kinds of teeth of varying

152 shapes may indicate shorter transport distance, whereas many similar kinds of teeth may be more

153 affected by transport (either carried in or winnowed). It is important to consider that differences

154 in substrate could have implications not addressed in this preliminary study of hydrodynamic

155 tooth behavior. Further work exploring these questions, including interactions with different

156 substrate types, will be necessary.

157 The variable transportability of shed and root-bearing teeth has important implications for

158 taphonomic reconstructions. For example, shed theropod and sauropod teeth in Morrison quarries

159 and microsites have previously been used in paleoecological reconstructions (Bakker and Bir,

160 2004), inferences of feeding behaviors (Jennings and Hasiotis, 1996), and suggested for

161 utilization in population studies (Erickson, 1996). However, prior to such inferences,

162 hydrodynamic properties, such as relative transport potential, must be taken into consideration in

163 order to gain a better understanding of whether the presence of shed teeth represent an

164 allochthonous or autochthonous component to such quarries.

165 The results shown here indicate that, not only does tooth morphology matter in transport

166 potential, but the interaction between hydrodynamic properties of tooth shape and conditions in

167 the depositional environment that contribute to microfossil accumulations. These results suggest

168 that tooth shape and flow velocity interact to influence transport, but the hydrodynamic behavior 
169 of teeth becomes increasingly unpredictable at higher flow velocities, and therefore may limit our

170 ability to infer the taphonomic history of a microfossil assemblage from high-velocity

171 depositional environments. Although this study focused on just two common Jurassic taxa,

172 further experimental studies on the potential transportability of shed teeth of varying

173 morphologies and substrate conditions have the potential to indicate preservation biases in

174 bonebed and microfossil assemblages. Understanding the potential of such biases may influence

175 further interpretations of dinosaur population dynamics, paleoecology, and feeding behaviors.

176

177

178

179

180

181

182

\section{ACKNOWLEDGEMENTS}

We thank Collin Dischler (UWO) for assistance in producing tooth casts, Patty Ralrick, Mike Newbry (TMP), and James Farlow (IPFW), stimulating discussion and experimental design, Tom Suszek and Ben Sanderfoot (UWO) and Roy Plotnick (UIC) for assistance in running the flume systems. We also thank Heinrich Mallison (MfN) for encouragement and assistance at PeerJ. Special thanks to our PeerJ reviewers (Peter Dodson and Jordan Mallon), and editor (John Hutchinson) for helpful comments and suggestions.

\section{REFERENCES}

ARgast, S., Farlow, J.O., GABET, R.M., AND BRINKMAN, D.L., 1987, Transport-induced abrasion of fossil reptilian teeth: implications for the existence of Tertiary dinosaurs in the Hell Creek Formation, Montana. Geology 15: 927-930.

Aslan, A., AND BeHRENSMEYER, A.K., 1975, Taphonomy and a time resolution of bone assemblages in a contemporary fluvial system: the East Fork River, Wyoming. PALAIOS, v. 11, p. $411-421$.

BAKKER, R.T., 1997, Raptor family values: allosaur parents brought giant carcasses in to their lair to feed their young. D.L. Wolberg, E. Stump, G.D. Rosenberg (Eds.), Dinofest International, Academy of Natural Sciences, Philadelphia: 1997. pp. 51-63

BAKKER, R.T., AND BIR, G., 2004, Dinosaur crime scene investigations: theropod behavior at Como Bluff, Wyoming, and the evolution of birdness. In: Currie P.J, Koppelhus E.B, Shugar M.A, Wright J.L, editors. Feathered dragons. Indiana University Press; Bloomington, IN: 2004. pp. 301-342.

BEHRENSMEYER, A.K., 1975, The taphonomy and paleoecology of Plio-Pleistocene vertebrate assemblages east of Lake Rudolf, Kenya: Bulletin of the Museum of Comparative Zoology, v. 145, p. 473-574. 
200

201

202

203

204

205

206

207

208

209

210

211

212

213

214

215

216

217

218

219

220

221

222

223

224

225

226

227

228

229

230

231

232

233

BLOB, R.W. AND FIORILLO, A.R., 1996, The significance of vertebrate microfossil size and shape distributions for faunal abundance reconstructions: a Late Cretaceous example. Paleobiology, 22:422-435.

BLOB, R.W., 1997, Relative hydrodynamic dispersal potentials of soft-shelled turtle elements: implications for interpreting skeletal sorting in assemblages of non-mammalian terrestrial vertebrates. PALAIOS, v. 12, p. 151-164.

BOAZ, N. and BEHRENSMEYER, A.K., 1976, Hominid taphonomy: transport of human skeletal parts in an artificial fluviatile environment; American Journal of Physical Anthropology, v. 45 , p. $53-60$.

BREITHAUPT, B.H., 2001, The case of "Big Al" the Allosaurus: a study in paleodetective partnerships, p. 95-106 In Santucci, V.L. and McClelland, L. (eds.) Proceedings of the 6th Fossil Resource Conference (National Park Service, U.S. Department of the Interior, Geologic Resources Division Technical Report (NPS/NRGRD/GRDTR-01/01) p. 226.

BREKHUS, P.J. AND ARMSTRONG, W.D., 1935, A method for the separation of enamel, dentin, and cementum. Journal of Dental Research 15(1): 23-29.

COARD, R., 1999, One bone, two bones, wet bones, dry bones: Transport potentials under experimental controls: Journal of Archaeological Science, v. 26, p. 1369-1375.

COARD, R. AND DENNELL, R.W., 1995, Taphonomy of some articulated skeletal remains: Transport potential in an artificial environment: Journal of Archaeological Science, v. 22, p. 441-448.

D’Emic, M.D., Whitlock, J.A., SMith, K.M., Fisher, D.C., AND Wilson, J.A., 2013, Evolution of high tooth replacement rates in sauropod dinosaurs. PLoS ONE 8(7): e69235. doi:10.1371/journal.pone.0069235

DeRSTLER, K. AND Myers, J.M. 2008. Taphonomy of the Tyrannosaurus rex Peck's Rex from the Hell Creek Formation of Montana. In Tyrannosaurus rex: The Tyrant King, P Larson and K Carpenter (eds) p. 75-82. Indiana University Press.

DODSON, P., 1973, The significance of small bones in paleoecological interpretation: Contributions to Geology, v. 12, p. 15-19.

ERICKSON G.M., 1996, Incremental lines of von Ebner in dinosaurs and the assessment of tooth replacement rates using growth line counts. Proceedings of the National Academy of Sciences 93: 14623-14627.

HANSON, C.B., 1980, Fluvial taphonomic processes: models and experiments, in Behrensmeyer, A.K., and Hill, A., eds., Fossils in the Making: University of Chicago Press, Chicago, p. $156-181$. 
234

235

236

237

238

239

240

241

242

243

244

245

246

247

248

249

250

251

252

253

254

255

256

257

258

259

260

261

262

263

264

265

266

JenNings, D.S., AND HASIOTIS S.T., 2006, Taphonomic analysis of a dinosaur feeding site using geographic information systems (GIS), Morrison Formation, southern Bighorn Basin, Wyoming, USA. Palaios 21(5): 480-492.

LEHMAN, T.M. AND COULSON, A.B., 2002, A juvenile specimen of the sauropod dinosaur Alamosaurus sanjuanensis from the Upper Cretaceous of Big Bend National Park, Texas. Journal of Paleontology 76(1):156-172.

NASTI, A., 2005, Dragging and scattering of camelid bones by fluvial action in the Real Grande Gorge, Province of Catamarea, Southern Argentinean Puna. Journal of Taphonomy 3(4): 173-183.

Peterson, J.E. AND BigalKe, C.L., 2013, Hydrodynamic behaviors of pachycephalosaurid domes in controlled fluvial settings: a case study in experimental dinosaur taphonomy. Palaios 28(5): 285-292.

ROACH, B.T. AND BRINKMAN, D.L., 2007, A reevaluation of cooperative pack hunting and gregariousness in Deinonychus antirrhopus and other nonavian theropod dinosaurs. Bulletin of the Peadoby Musuem of Natural History 48(1): 103-138.

ROGERS, R.R., AND BRADY, M.E., 2010, Origins of microfossil bonebeds: insights from the Upper Cretaceous Judith River Formation of north-central Montana. Paleobiology 36(1): 80-112.

SERENO, P.C. AND WILSON, J.A., 2005, Structure and evolution of a sauropod tooth battery. In: Curry Rogers KA, Wilson JA, editors. The sauropods: evolution and paleobiology. Berkeley: University of California Press. 157-177.

SOKAL, R.R. AND RoHLF, F.J. 1995. Biometry. W.H. Freeman and Company, New York: 887 p.

TRAPANI, J., 1998, Hydrodynamic sorting of avian skeletal remains. Journal of Archaeological Science, v. 25, p. 477-487.

VOORHIES, M.R., 1969, Taphonomy and population dynamics of an early Pliocene vertebrate fauna, Knox County, Nebraska: University of Wyoming Contributions to Geology Special Paper, v. 1, p. 1-69.

WILSON, L.E., 2008, Comparative taphonomy and paleoecological reconstruction of two microvertebrate accumulations from the Late Cretaceous Hell Creek Formation (Maastrichtian), eastern Montana. Palaios 23(5): 289-297.

WoOD, M.W., THOMAS, R.G. and VISSER, J., 1988, Fluvial processes and vertebrate taphonomy: the Upper Cretaceous Judith River Formation, South-Central Dinosaur Provincial Park, Alberta, Canada: Palaeogeography, Palaeoclimatology, Palaeoecology, v. 66, p. 127-143. 
FIGURE 1: Photographs and cross-sectional outlines of cast specimens used in the flume experiment. A) Root-bearing Camarasaurus tooth (UWO-VPC-2013.003), B) Root-bearing Allosaurus tooth (UWO-VPC-2013.001), C) Shed Camarasaurus tooth (UWO-VPC-2013.004), and D) Shed Allosaurus tooth (UWO-VPC-2013.002). Scale bar $=5 \mathrm{~cm}$.

FIGURE 2: Recirculating flume facility at UW Oshkosh where experiments were conducted. A) Cross-sectional view, B) Side view, C) Schematic diagram of recirculating flume.

FIGURE 3: Examples of orientations of tooth casts. A) Root-bearing casts oriented perpendicular to flow, B) root-bearing casts oriented parallel to flow, C) shed casts oriented perpendicular to flow, D) shed casts oriented parallel to flow. E) Example of root-bearing Allosaurus tooth cast oriented parallel to flow, F) example of shed Camarasaurus tooth oriented perpendicular to flow.

FIGURE 4: Bar chart of transport distances for tooth casts placed A) perpendicular or B) parallel to flow. Error bars represent standard error.

FIGURE 5: A) Average transport distance of cast tooth specimens versus velocity ranges for specimens tested perpendicular to flow and B) parallel to flow. Error bars represent standard 282 error.

283 TABLE 1: Dimensions and Properties of Cast Tooth Specimens

TABLE 2: Two-factor ANOVA (A) and Bonferroni multiple comparison test (B) results for tooth cast transport distances tested perpendicular to flow; Two-factor ANOVA (C) and Bonferroni multiple comparison test (D) results for tooth cast transport distances tested parallel to flow. Adjusted P value refers to the exact multiplicity-adjusted $p$-value calculated in Prism version 6.0d. All values based on log-transformed data.

\section{SUPPORTING DATA}

290 SUPPORTING TEXT 1: Scan data 3D models of tooth cast specimens.

291 SUPPORTING FIGURE 1: PDF of 3D model of root-bearing Allosaurs tooth (UWO-VPC-

292 2013.01).

293 SUPPORTING FIGURE 2: PDF of 3D model of shed Allosaurus tooth (UWO-VPC-2013.02).

294 SUPPORTING FIGURE 3: PDF of 3D model of root-bearing Camarasaurus tooth (UWO-VPC295 2013.03).

296 SUPPORTING FIGURE 4: PDF of 3D model of shed Camarasaurus tooth (UWO-VPC297 2013.04). 


\section{Figure 1}

Photographs and cross-sectional outlines of cast specimens used in the flume experiment.

A) Root-bearing Camarasaurus tooth (UWO-VPC-2013.003), B) Root-bearing Allosaurus tooth (UWO-VPC-2013.001), C) Shed Camarasaurus tooth (UWO-VPC-2013.004), and D) Shed Allosaurus tooth (UWO-VPC-2013.002). Scale bar $=5 \mathrm{~cm}$.
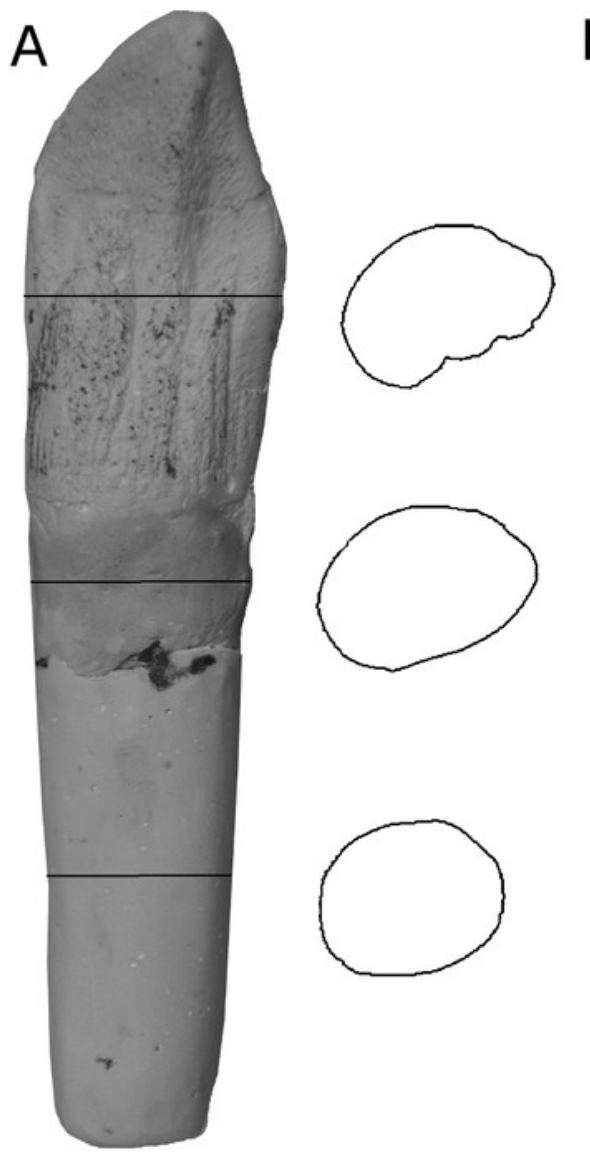

B
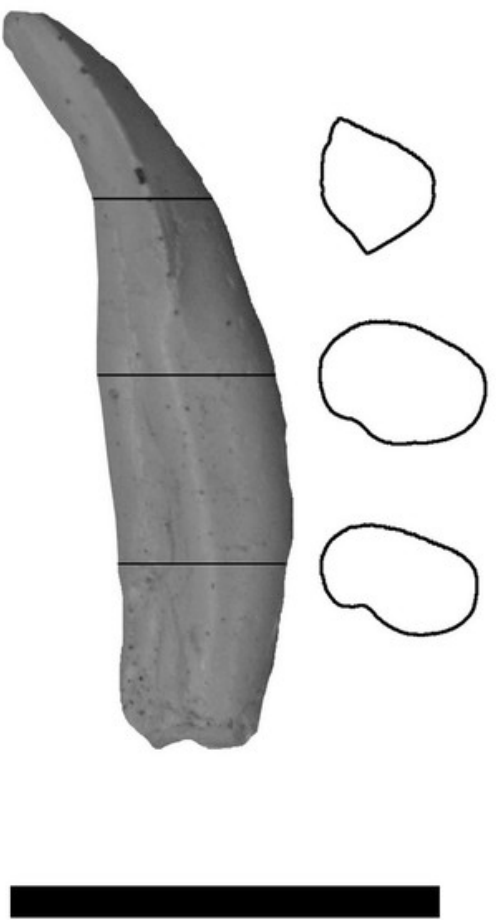

C
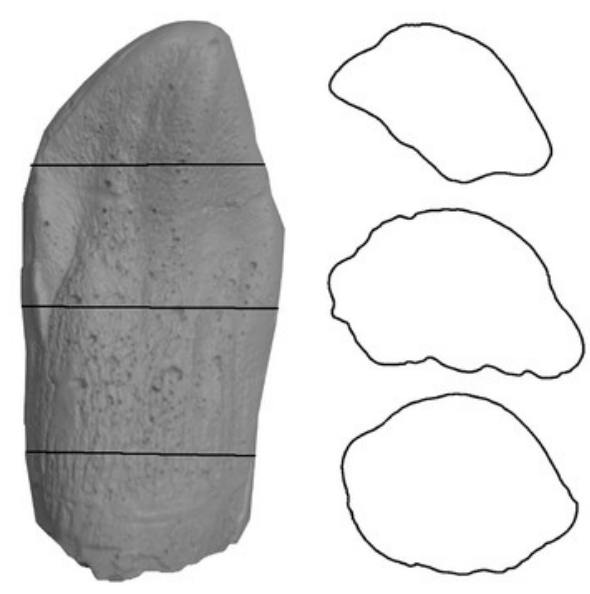

D

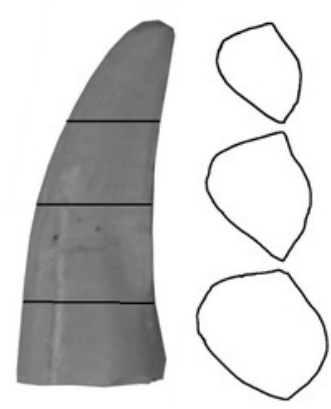




\section{Figure 2}

Recirculating flume facility at UW Oshkosh where experiments were conducted.

A) Cross-sectional view, B) Side view, C) Schematic diagram of recirculating flume.
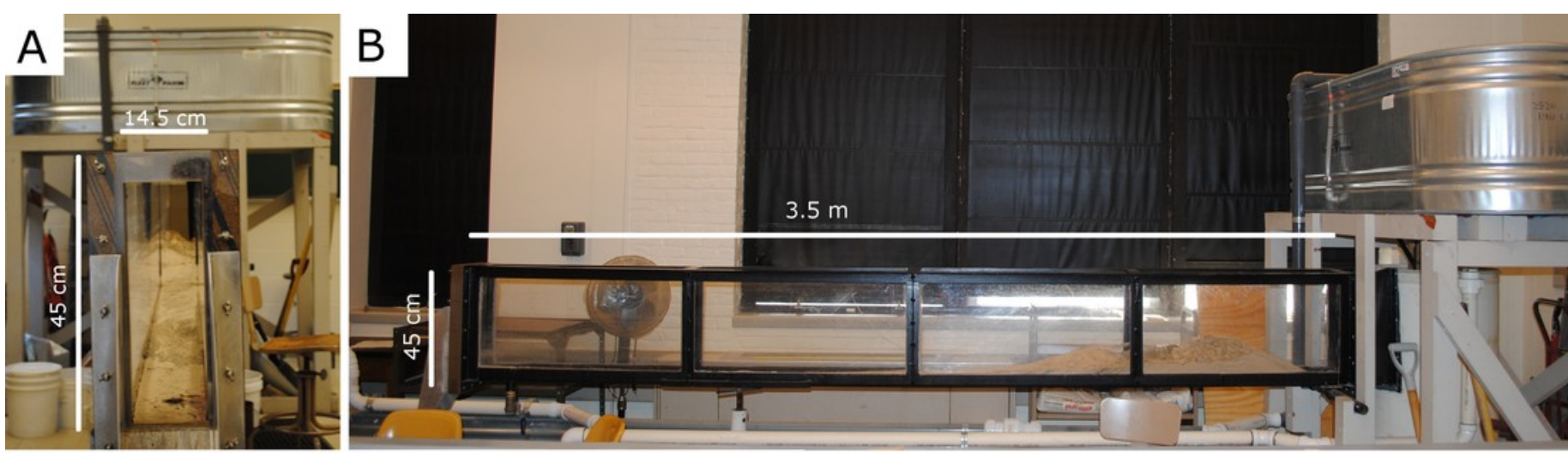

C

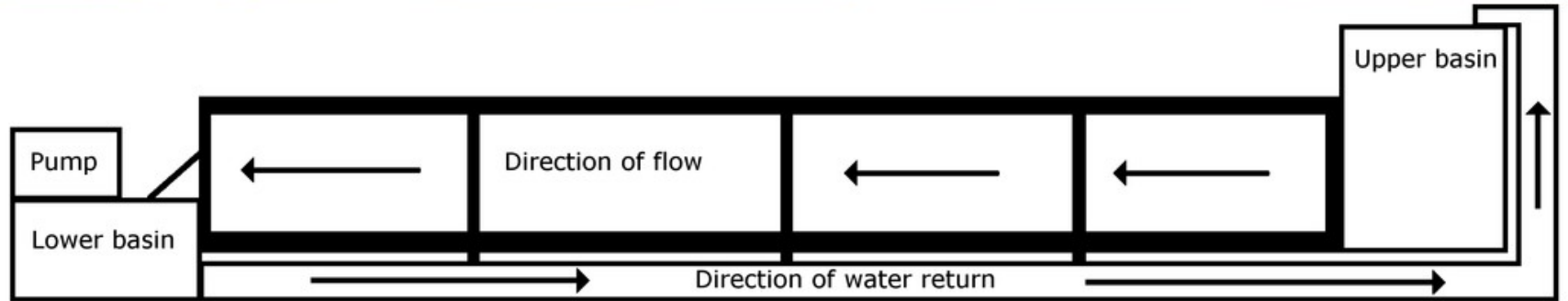




\section{Figure 3}

Examples of orientations of tooth casts.

A) Root-bearing casts oriented perpendicular to flow, B) root-bearing casts oriented parallel to flow, C) shed casts oriented perpendicular to flow, D) shed casts oriented parallel to flow. E) Example of root-bearing Allosaurus tooth cast oriented parallel to flow, F) example of shed Camarasaurus tooth oriented perpendicular to flow.

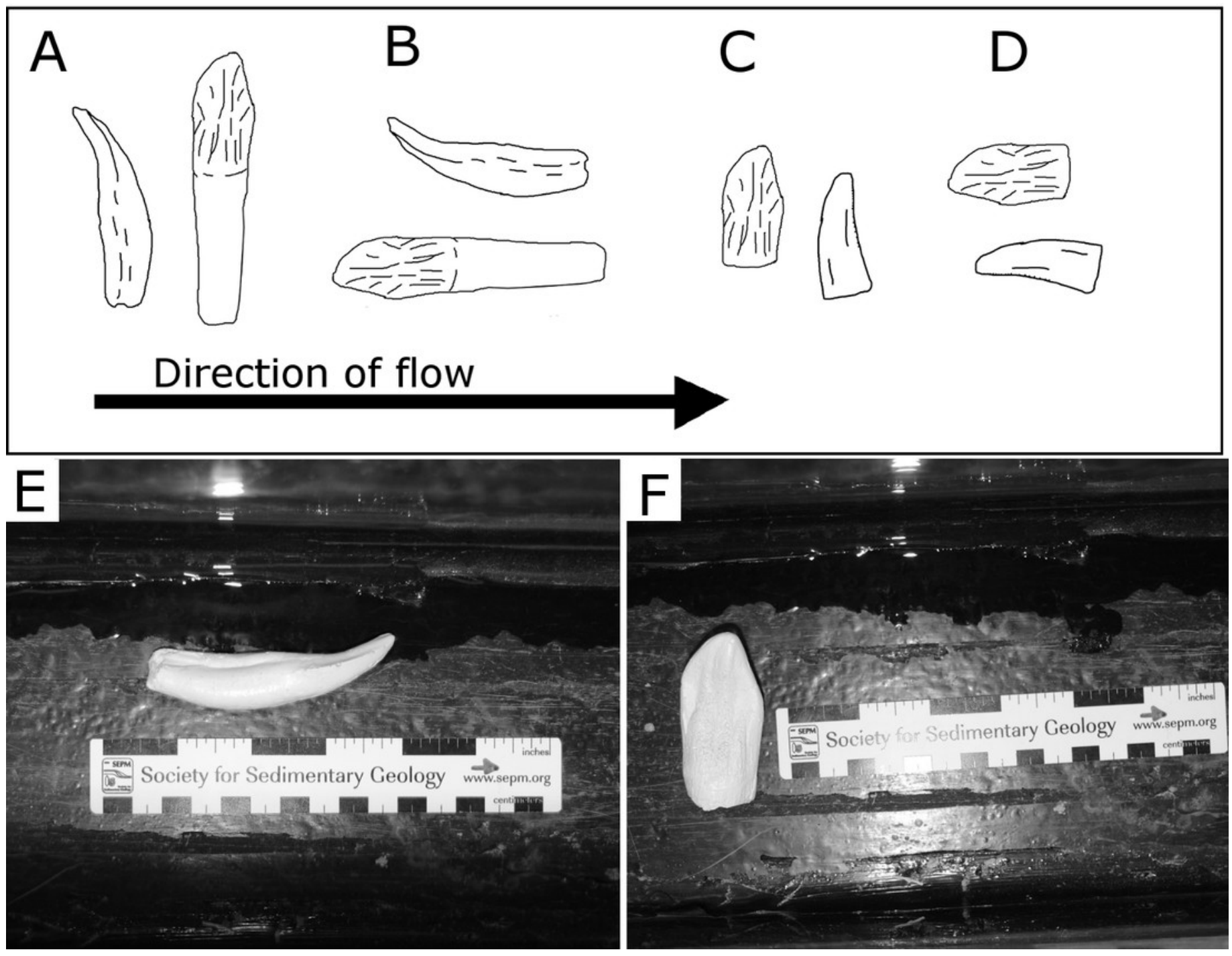




\section{Figure 4}

Bar chart of transport distances for tooth casts.

Placed A) perpendicular or B) parallel to flow. Error bars represent standard error.

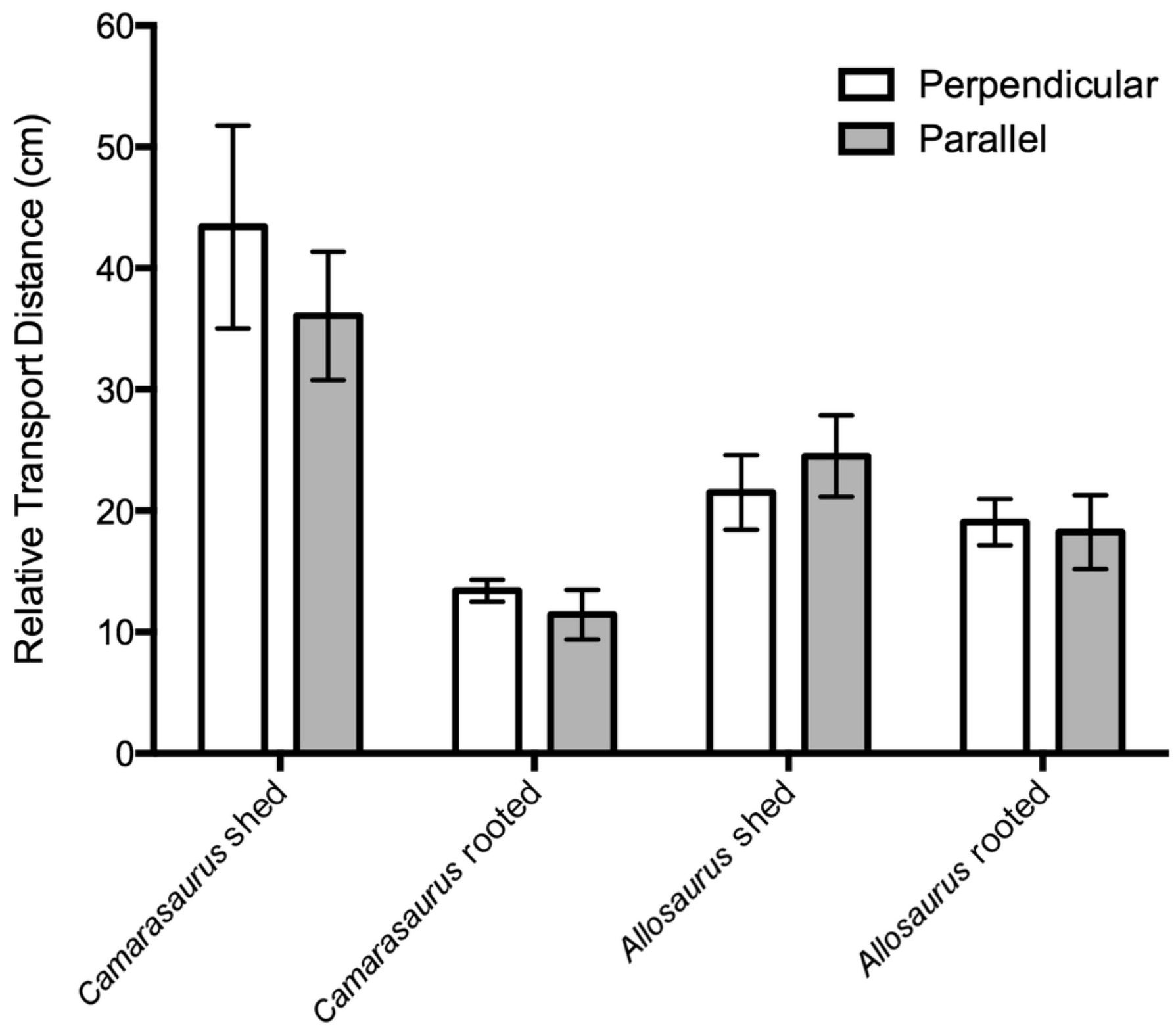

Tooth Shape 


\section{Figure 5}

Average transport distance of cast tooth specimens versus velocity ranges.

A) Specimens tested perpendicular to flow and B) parallel to flow. Error bars represent standard error. 
A

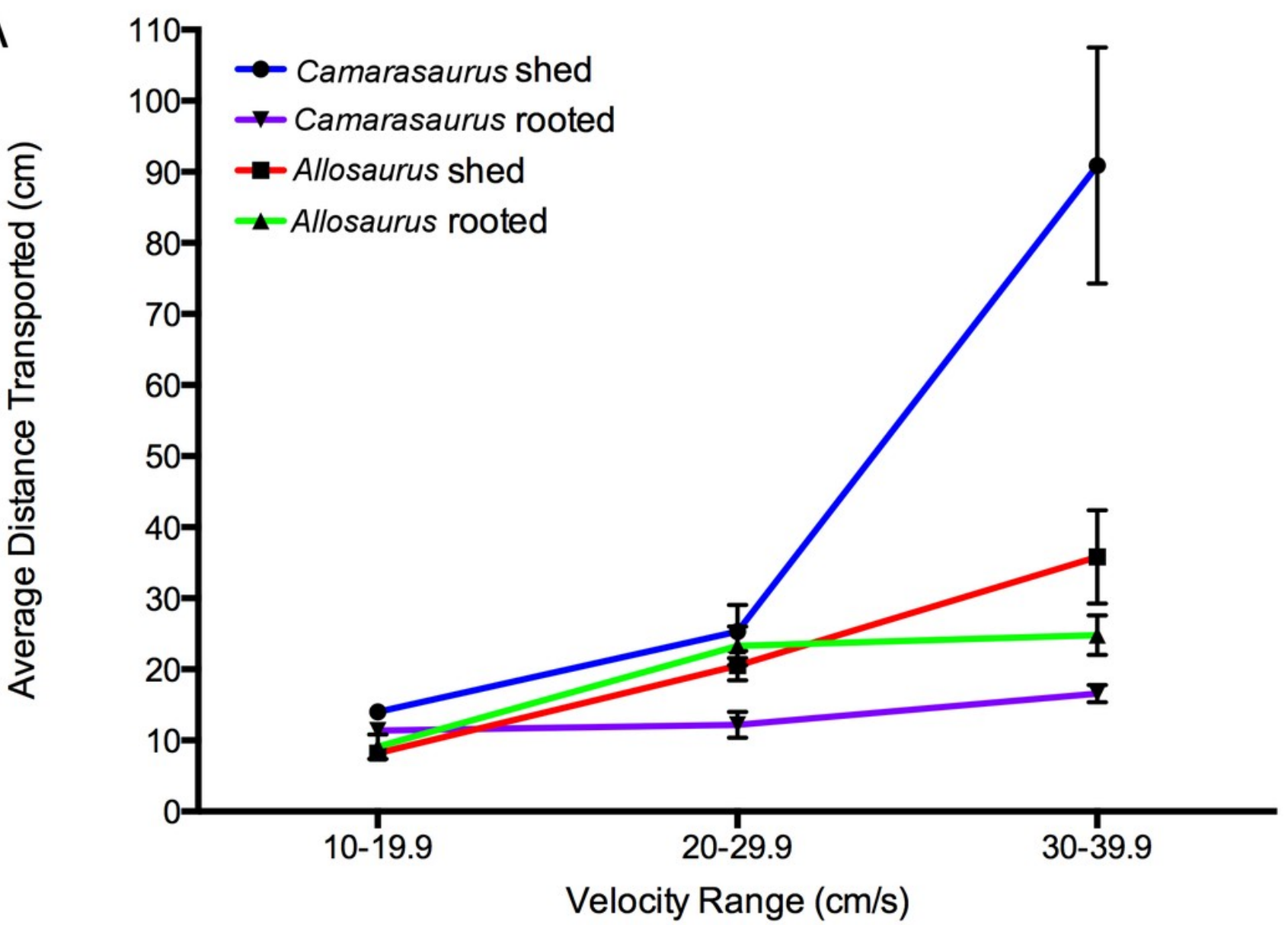

B

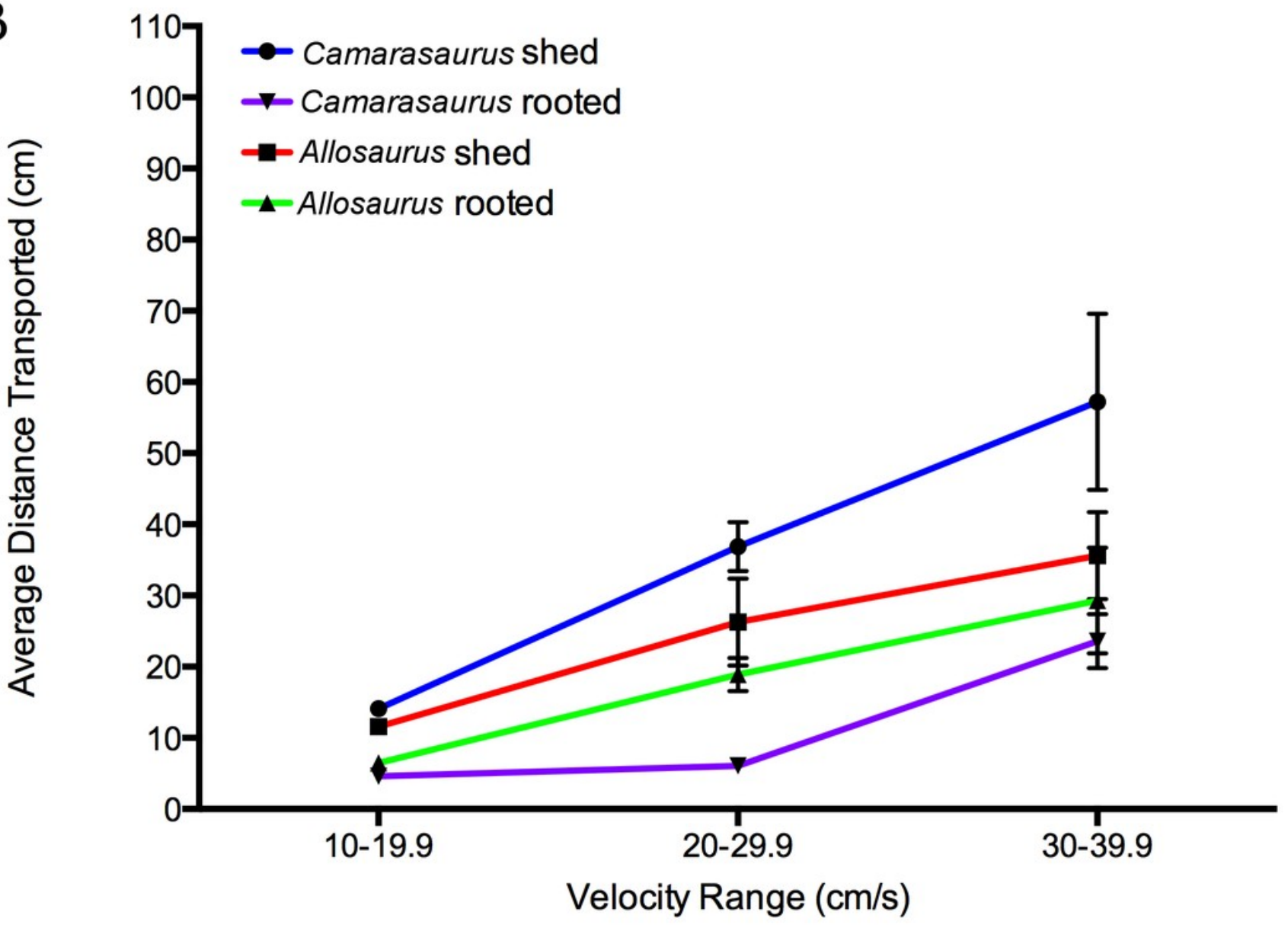




\section{Table 1 (on next page)}

Dimensions and Properties of Cast Tooth Specimens

Mass of casts $(\mathrm{g})$, Length of casts $(\mathrm{mm})$, Width of casts $(\mathrm{mm})$, Density $\left(\mathrm{g} / \mathrm{cm}^{3}\right)$, Shape. 
TABLE 1

\begin{tabular}{|c|c|c|c|c|c|}
\hline Tooth Specimen & Mass of cast $(\mathbf{g})$ & Length $(\mathbf{m m})$ & Width $(\mathbf{m m})$ & Density $\mathbf{( g / \mathbf { c m } ^ { 3 } )}$ & Shape \\
\hline Camarasaurus $(\mathrm{shed})$ & 29 & 61 & 29 & 1.45 & Compact \\
\hline Camarasaurus (rooted) & 60 & 122 & 29 & 1.5 & Elongate \\
\hline Allosaurus (shed) & 8.2 & 44 & 19 & 1.49 & Conical \\
\hline Allosaurus (rooted) & 19 & 82 & 19 & 1.52 & Elongate \\
\hline
\end{tabular}




\section{Table 2 (on next page)}

Statistical Tests Performed on Transport Data 
2A: Two-factor ANOVA table for perpendicular

$\begin{array}{lrrr}\text { Source of Variation } & \text { SS } & \text { DF } & \text { MS } \\ \text { Interaction } & 1.367 & 6 & 0.2278 \\ \text { Flow Velocity } & 5.091 & 2 & 2.546 \\ \text { Tooth Type } & 2.093 & 3 & 0.6977 \\ \text { Residual } & 5.058 & 108 & 0.04683\end{array}$

$\begin{array}{rr}\mathrm{F} & \mathrm{P} \text { value } \\ 4.87 & \mathrm{P}=0.0002 \\ 54.35 & \mathrm{P}<0.0001 \\ 14.90 & \mathrm{P}<0.0001\end{array}$

2B: Two-factor ANOVA table for parallel

$\begin{array}{lrrr}\text { Source of Variation } & \text { SS } & \text { DF } & \text { MS } \\ \text { Interaction } & 0.9006 & 6 & 0.1501 \\ \text { Flow Velocity } & 6.715 & 2 & 3.357 \\ \text { Tooth Type } & 5.495 & 3 & 1.832 \\ \text { Residual } & 4.622 & 108 & 0.04280\end{array}$

$\begin{array}{rr}\mathrm{F} & \mathrm{P} \text { value } \\ 3.507 & \mathrm{P}=0.0033 \\ 78.45 & \mathrm{P}<0.0001 \\ 42.80 & \mathrm{P}<0.0001\end{array}$

2C: Bonferroni Multiple Comparison Test results for perpendicular

Comparison

Low Flow (10-19.9 cm/s)

Camarasaur shed vs. Allosaur shed

Camarasaur shed vs. Allosaur rooted

Camarasaur shed vs. Camarasaur rooted

Allosaur shed vs. Allosaur rooted

Allosaur shed vs. Camarasaur rooted

Allosaur rooted vs. Camarasaur rooted

Intermediate Flow (20-29.9 cm/s)

Camarasaur shed vs. Allosaur shed

Camarasaur shed vs. Allosaur rooted

Camarasaur shed vs. Camarasaur rooted

Allosaur shed vs. Allosaur rooted

Allosaur shed vs. Camarasaur rooted

Allosaur rooted vs. Camarasaur rooted

High Flow (30-39.9 cm/s)

Camarasaur shed vs. Allosaur shed

Camarasaur shed vs. Allosaur rooted

Camarasaur shed vs. Camarasaur rooted

Allosaur shed vs. Allosaur rooted

Allosaur shed vs. Camarasaur rooted

Allosaur rooted vs. Camarasaur rooted

Mean Diff. $\quad 95 \%$ CI of diff.

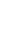

t DF Adjusted P

Value

$\begin{array}{rrrrr}0.2682 & 0.008091 \text { to } 0.5283 & 2.771 & 108 & 0.0395 \\ 0.2569 & -0.00324 \text { to } 0.5170 & 2.654 & 108 & 0.0549 \\ 0.09858 & -0.1615 \text { to } 0.3587 & 1.019 & 108 & >0.9999 \\ -0.01133 & -0.2715 \text { to } 0.2488 & 0.117 & 108 & >0.9999 \\ & & 1 & & \\ -0.1696 & -0.4298 \text { to } 0.09048 & 1.753 & 108 & 0.4949 \\ -0.1583 & -0.4184 \text { to } 0.1018 & 1.636 & 108 & 0.6289\end{array}$

$\begin{array}{rrrrr}0.07721 & -0.1829 \text { to } 0.3373 & 0.797 & 108 & >0.9999 \\ 0.03548 & -0.2246 \text { to } 0.2956 & 0.366 & 108 & >0.9999 \\ & & 6 & & \\ 0.3358 & 0.07571 \text { to } 0.5960 & 3.470 & 108 & 0.0045 \\ -0.04173 & -0.3019 \text { to } 0.2184 & 0.431 & 108 & >0.9999 \\ & & 2 & & \\ 0.2586 & -0.00149 \text { to } 0.5187 & 2.672 & 108 & 0.0522 \\ 0.3004 & 0.04024 \text { to } 0.5605 & 3.103 & 108 & 0.0147\end{array}$

$\begin{array}{lrrrr}0.3733 & 0.1131 \text { to } 0.6334 & 3.857 & 108 & 0.0012 \\ 0.4872 & 0.2271 \text { to } 0.7473 & 5.034 & 108 & <0.0001 \\ 0.6446 & 0.3845 \text { to } 0.9047 & 6.660 & 108 & <0.0001 \\ 0.1140 & -0.1462 \text { to } 0.3741 & 1.177 & 108 & >0.9999 \\ 0.2713 & 0.01123 \text { to } 0.5315 & 2.804 & 108 & 0.0359 \\ 0.1574 & -0.1027 \text { to } 0.4175 & 1.626 & 108 & 0.6409\end{array}$

2D: Bonferroni Multiple Comparison Test results for parallel

\begin{tabular}{|c|c|c|c|c|c|}
\hline Comparison & Mean Diff. & $95 \%$ CI of diff. & $\mathrm{t}$ & DF & $\begin{array}{r}\text { Adjusted P } \\
\text { Value }\end{array}$ \\
\hline $\begin{array}{l}\text { Low Flow }(10-19.9 \mathrm{~cm} / \mathrm{s}) \\
\text { Camarasaur shed vs. Allosaur shed }\end{array}$ & 0.08950 & -0.1592 to 03382 & 09675 & 108 & $>09999$ \\
\hline
\end{tabular}


Camarasaur shed vs. Allosaur rooted

Camarasaur shed vs. Camarasaur rooted

Allosaur shed vs. Allosaur rooted

Allosaur shed vs. Camarasaur rooted

Allosaur rooted vs. Camarasaur rooted

Intermediate Flow (20-29.9 cm/s)

Camarasaur shed vs. Allosaur shed

Camarasaur shed vs. Allosaur rooted

Camarasaur shed vs. Camarasaur rooted

Allosaur shed vs. Allosaur rooted

Allosaur shed vs. Camarasaur rooted

Allosaur rooted vs. Camarasaur rooted

High Flow (30-39.9 cm/s)

Camarasaur shed vs. Allosaur shed

Camarasaur shed vs. Allosaur rooted

Camarasaur shed vs. Camarasaur rooted

Allosaur shed vs. Allosaur rooted

Allosaur shed vs. Camarasaur rooted

Allosaur rooted vs. Camarasaur rooted

$\begin{array}{rrrrr}0.3681 & 0.1195 \text { to } 0.6168 & 3.979 & 108 & 0.0008 \\ 0.5345 & 0.2858 \text { to } 0.7831 & 5.777 & 108 & <0.0001 \\ 0.2786 & 0.02995 \text { to } 0.5273 & 3.011 & 108 & 0.0194 \\ 0.4450 & 0.1963 \text { to } 0.6936 & 4.810 & 108 & <0.0001 \\ 0.1664 & -0.08231 \text { to } 0.4150 & 1.798 & 108 & 0.4497 \\ & & & & \\ 0.1847 & -0.06400 \text { to } 0.4333 & 1.996 & 108 & 0.2908 \\ 0.3013 & 0.05265 \text { to } 0.5500 & 3.257 & 108 & 0.0090 \\ 0.8272 & 0.5785 \text { to } 1.076 & 8.941 & 108 & <0.0001 \\ 0.1167 & -0.1320 \text { to } 0.3653 & 1.261 & 108 & >0.9999 \\ 0.6425 & 0.3939 \text { to } 0.8912 & 6.945 & 108 & <0.0001 \\ 0.5259 & 0.2772 \text { to } 0.7745 & 5.684 & 108 & <0.0001 \\ & & & & \\ 0.1819 & -0.06672 \text { to } 0.4306 & 1.967 & 108 & 0.3108 \\ 0.3071 & 0.05845 \text { to } 0.5558 & 3.320 & 108 & 0.0074 \\ 0.3655 & 0.1168 \text { to } 0.6141 & 3.950 & 108 & 0.0008 \\ 0.1252 & -0.1235 \text { to } 0.3738 & 1.353 & 108 & >0.9999 \\ 0.1835 & -0.06512 \text { to } 0.4322 & 1.984 & 108 & 0.2989 \\ 0.05837 & -0.1903 \text { to } 0.3070 & 0.6309 & 108 & >0.9999\end{array}$

